\title{
Tropical Atmospheric Response to Decadal Changes in the Atlantic Equatorial Mode.
}

\author{
Losada T. ${ }^{(1)}$, B. Rodríguez-Fonseca ${ }^{(1,2)}$
}

(1) Departamento de Física de la Tierra, Astronomía y Astrofísica I, Geofísica y Meteorología. UCM, Av. Complutense s/n, 28040 Madrid (Spain).

${ }^{(2)}$ Instituto de Geociencias (CSIC-UCM), Facultad de CC. Físicas, Plaza de Ciencias 1, 28040 Madrid (Spain).

Climate Dynamics, 2015. Accepted. DOI 10.1007/s00382-015-2897-2

\begin{abstract}
It has been shown that the atmospheric response to the Atlantic Equatorial Mode is nonstationary. After the 1970's, Sea Surface Temperature (SST) anomalies in the tropical Atlantic are able to alter the atmosphere in the tropical Pacific via modifications of the Walker circulation. Such changes could be related to the differences in the background state of the global SSTs before and after the 1970's, but also to changes in the interannual Equatorial Mode itself.
\end{abstract}

In this work we first describe the differences in the interannual Equatorial Mode before and after the 1970's. Then we use two AGCMs to perform different sensitivity experiments, changing the spatial structure of the Equatorial Mode, and we explore the differences in the atmospheric response over the tropical Pacific region to each of the SST patterns considered.

It is shown that the changes in the Walker Atlantic-Pacific cell produced by the EM are stronger after the 1970's, and are reinforced by the change in the impact of the EM over the Indian Ocean and the Maritime Continent. 
It is also shown that, although the Atlantic-Pacific connection is established by the aforementioned changes in the Walker circulation between the two basins, the modulation of the Indian sector is crucial for a realistic simulation of such connection by climate models.

Keywords: Tropical Atlantic; Climate Variability; Equatorial Mode; Tropical Teleconnections

\section{Introduction}

The Atlantic Equatorial Mode (EM) is the first mode of variability in the Tropical Atlantic during boreal summer (Xie and Carton, 2004); it is characterized by the presence of anomalous SST in the eastern part of the equatorial Atlantic, with the concomitant displacement of the convective region (Zebiak, 1993), showing its maximum SST anomalies during boreal summer. Polo et al. (2008) describe it as a time evolving pattern in which anomalous SSTs start at the Angola/Benguela region and propagate westward and equatorward (Zebiak, 1993; RuizBarradas et al., 2000), decaying in the western part of the basin. The dynamical mechanisms of the EM are similar to those described for the Pacific el Niño: the Bjerknes feedback and the equatorial waves dynamics (Bjerknes, 1969; Zebiak, 1993; Keenlyside and Latif, 2007; Jansen et al., 2009).

The impacts of the EM in the adjacent regions have been widely study. It is well known that it affects the West African Monsoon in a way that an anomalous warming (cooling) in the eastern tropical Atlantic in summer is related to an increase (decrease) of rainfall over the Gulf of Guinea and the opposite over the Sahel (Janicot et al., 1992; 1998; Rowell et al., 1995; Vizy and Cook, 2002; Losada et al., 2010a; 2012a; Mohino et al., 2011; among others). Also, the EM affects Brazilian precipitation in the region of Nordeste through the shift of the Intertropical Convergence Zone (ITCZ); a warming (cooling) of the tropical Atlantic in boreal summer produces a southward (northward) shift of the ITCZ and a increase (decrease) of the rainfall over Nordeste (Giannini et al., 2004). 
Several studies describe a possible impact of the EM in the extratropics in early winter through the propagation of extratropical Rossby waves (Cassou et al. 2004, Garcia-Serrano et al., 2008); as well as its effect in the Mediterranean precipitation in summer (Losada et al., 2012b).

Regarding its impacts in remote tropical ocean basins, it has been shown that the atmospheric response to the Atlantic Equatorial Mode (EM) is non-stationary. After the 1970's, SST anomalies in the tropical Atlantic are able to alter the atmosphere in the tropical Pacific via modifications of the Walker circulation (Wang et al., 2006; Polo et al., 2008; RodriguezFonseca et al., 2009; Wang et al., 2009; Losada et al., 2010b; Ding et al., 2011; Martin-Rey et al., 2012; Keenlyside et al. 2013). These anomalies also alter the circulation over the Indian sector leading to anomalous subsidence over India (Kucharski et al., 2007; 2008; 2009; Wang et al., 2009; Losada et al., 2010b). Such impacts of the tropical Atlantic variability over the rest of the tropical ocean basins have not been documented for the period before the 1970's.

What causes these changes is an open question that deserves further investigation. On the one hand, there exist modes of variability in the global SSTs at multidecadal scales, such as the Atlantic Multidecadal Oscillation (AMO; Knight et al., 2005) and the Inter-Decadal Pacific Oscillation (IPO; Zhang et al., 1997), which could be responsible for different atmospheric responses to a same interannual mode of variability. On the other hand, it is plausible that the interannual mode itself had suffered changes in its spatial configuration at multidecadal scales, and that these changes had produced different impacts in the atmospheric circulation.

Regarding the latter, the possibility of existence of different configurations of the Atlantic Equatorial Mode is consistent with results shown in previous studies. Nnamchi et al. (2011) differentiate two different modes of variability characterized by strong loadings of SST anomalies in the tropical Atlantic in summer, the EM and the South Atlantic Ocean Dipole (SAOD), with different dynamics involved. For its part, Richter et al. (2012) divide the Atlantic 
Niños in "canonical" and "non-canonical" events, also depending on their driving mechanisms. According to their results, the canonical events are characterized by vertical advection consistent with an ENSO-like mechanisms in which a weakening of the trade winds produces a change in the thermocline slope and a warming in the eastern part of the equatorial ocean basin, while the non-canonical events are dominated by meridional and zonal advection and could be linked in some way to the meridional mode.

In this work, we first explore the possibility of the existence of two different configurations of the EM, with maximum presence before and after the 70's. After these two configurations of the EM are confirmed, we describe the differences in their effects over the tropical Pacific region, focusing in its possible role in the Atlantic-Pacific connection described by RodriguezFonseca et al. (2009).

The paper is structured as follows: Section 2 shows a description of the data and model used, together with the methodology applied in the study. The main results of the work are presented in Section 3, describing both the decadal differences in the EM (Section 3.1) and the different responses to the two configurations of the EM (Section 3.2). Finally, Section 4 provides a summary and a discussion of the results of the work together with the main conclusions.

\section{Models, Data and Methodology}

We perform sensitivity experiments with two different AGCMs: the UCLA AGCM version 7.3 (Mechoso et al., 2000; Richter et al. 2008), which is a state of the art model of the global atmosphere with a resolution of $2^{\circ}$ lat $\times 2.5^{\circ}$ lon and 29 vertical sigma levels; and the ICTP AGCM version 40 with a spectral truncation at a total wavenumber 30 (approximate resolution of $3.8^{\circ}$ in latitude and longitude) and 8 vertical levels. Details for this model can be found in Kucharski et al. (2007). 
The design of the experiments is the following: We run a control simulation in which we use as boundary condition climatological monthly means of SST averaged over the period 1950-1994. Then, we perform two sensitivity experiments, in which two different configurations of the Atlantic Equatorial Mode are added to the 1950-1994 monthly mean SSTs. In the first experiment (ATL_pre70 simulation) we add monthly anomalies consistent with the EM observed before the 1970's; while in the second experiment (ATL_post70 simulation) the SST monthly anomalies added in the tropical Atlantic have the structure of the EM observed after the 1970's.

For the ICTP-AGCM simulations, we perform 70-year run simulations for both the control and the sensitivity experiments, starting from the atmosphere at rest; we discard the first 10 years of each simulation.

Due to computational coast, each simulation performed with the UCLA-AGCM consist in a 10member ensemble in which each member of the ensemble differ from the others only in a slight perturbation of the initial conditions. The sensitivity experiments are seven-month long simulations covering the period from March to September.

The SSTs used along this work come from the Extended Reconstructed Sea Surface Temperature Dataset (ERSST.v3; Smith et al., 2008).

To calculate the EM anomalies used in our simulations we use the Atl3 index, defined as the monthly SST anomaly averaged over the region $\left[3^{\circ} \mathrm{S}-3^{\circ} \mathrm{N} ; 20^{\circ} \mathrm{W}-0^{\circ} \mathrm{E}\right]$ and for June-July-August (JJA), we apply an interannual filter to the data by computing the differences in the SST scores between each year and the following one (Stephenson et al., 2000; López-Parages and Rodríguez-Fonseca, 2012). This method not only removes a linear fit, but also can remove piecewise linear trends by converting them into constant terms (Stepbenson et al., 2000). In order to obtain an index representative of the long-term interannual variability of the tropical 
Atlantic, we compute the Atl3 over the whole XXth century. Then, we focus on the sub-periods chosen for the sensitivity experiments, that is 1950-1969 and 1975-1994, which are representative of a positive and a negative AMO phases (as in Martin-Rey et al., 2014), selecting those years in which the value of the Atl3 index averaged over JJA is larger (smaller) than 0,4 standard deviation and the sign of the index is positive (negative) for the three months. This gives us "positive" and "negative" years for each sub-period (Table 1), and we calculate the anomalous patterns of the EM for the AGCM experiments as the difference between the positive and negative years of each sub-period. The result of this calculation is shown in Figure 1.

We define the anomalous pattern of SST in the Atlantic Ocean for the region that covers the latitudes between $35^{\circ} \mathrm{S}$ and $5^{\circ} \mathrm{N}$. In order to avoid discontinuities in the SST fields, we applied a linear decrease of the SST anomalies in a 10-degree band polewards from those latitudes.

To evaluate the atmospheric response to the anomalous patterns of SST we calculate the differences between the results of the sensitivity experiments and the control simulation. To assess the significance of the response we apply a t-test of difference between means (von Storch and Zwiers, 1999), which estimates whether or not the averages of two samples have the same mean. Along this work we show the results for the analysis of the boreal summer season (July-August-September, JAS), highlighting the regions in which the differences between the sensitivity experiments and the control are significant at the $95 \%$ level.

\section{Results}

\subsection{Decadal differences in the Equatorial Mode:}

Before the 1970's the EM shows a dipolar structure with positive anomalies in the NE and negative in the SW southern tropical Atlantic. This mode has a structure similar to the South 
Atlantic Ocean Dipole (SAOD) described by Nnamchi et al. (2011), both in its boreal summer configuration (Figure 1a) and its seasonal evolution (not shown).

After the 1970's the SW pole of the mode disappears and the equatorial anomalies of SST reach the coast of South America. This mode is similar to the one that Rodriguez-Fonseca et al. (2009) and Losada et al. (2010b) found to have an impact in the tropical Pacific in boreal summer (Figure 1b), and its seasonal evolution (not shown) is consistent with the EM pattern described by Polo et al. (2008) and Losada et al. (2010a) as the canonical EM for the period 1979-2002. We have computed the statistical significance of the differences between the two patterns with a MonteCarlo test of 500 permutations, finding that the differences are significant at $90 \%$ level in the SW pole and at the equatioral band, west of $10^{\circ}$ (Figure 1 right).

The question about the opportunity of referring to these two patterns as the Equatorial Mode can be controversial. In this way, Nnamchi et al. (2011) argue that the SAOD and the EM are different modes of variability in which different dynamics operate, especially in the subtropical South Atlantic. Nevertheless, we have obtained the two patterns only by looking at the Atlantic variability over the equatorial region, and they also appear as the first mode of variability in the tropical Atlantic for each of the sub-periods of the study (not shown), as well as the SST pattern of the first modes of co-variability between tropical Atlantic SST and summer Mediterranean precipitation computed before and after the 1970's (Losada et al., 2012b). Also, as Nnamchi et al. (2011) have acknowledged, the evolution and peak of both the SAOD and the canonical EM occur during the same season (boreal summer) and the two events share similar equatorial aspects. In the light of all this, we think that is plausible to think that the EM and the SAOD are two different configurations of just one mode that describes the equatorial variability of the tropical Atlantic, and that shows multidecadal variations in its spatial pattern. The cause of these variations is beyond the scope of this study and will be the objective of future works. 


\subsection{Response to different EM and same climatology during JAS:}

Figure 2 shows the eddy-streamfunction response at 200-hPa for ATL_pre70 and ATL_post70 (first and second row) and for UCLA (left) and ICTP (right) simulations. The presence of a Gill-type response (Gill, 1980) to the warming in the tropical Atlantic is clear in the two simulations and for the two models, that show two anomalous anticyclones at both sides of the equator. The centers of them are located further west in ATL_post70 than in ATL_pre70 for the two models. The results also show a pair of cyclones straddling the equator in the Indian ocean, consistent with previous findings (Kucharski et al., 2009; Losada et al. 2010b). Over the Pacific sector, ICTP shows a second pair of cyclones covering the whole Pacific ocean in ATL_pre70, that are confined west of $180 \mathrm{~W}$ in ATL_post70. On the other hand, UCLA model show also a parir of cyclones over the equatorial Pacific east of $180 \mathrm{~W}$ for ATL_pre70 and ATL_post70 simulations.

The response of the two simulations (ATL_pre70; ATL_post70) in terms of anomalies of the velocity potential field at 200-hPa (Figure 3) and $925 \mathrm{hPa}$ (Figure 4), for the two models used along this work, depict the following situation:

Over the tropical Atlantic sector, results show great consistency betwen UCLA and ICTP AGCMs, both ATL_pre70 and ATL_post70 simulations show positive (negative) values at lower (upper) levels of the atmosphere, meaning that there are anomalous surface (upper level) convergence (divergence), and anomalous upward motions there.

When we move to the response over the tropical Pacific, we find more differences between models. At upper levels, ICTP simulations show positive anomalies of velocity potential at 200$\mathrm{hPa}$ in the tropical Pacific in both ATL_pre70 and ATL_post70, stronger for ATL_post70. At 925-hPa, also for ICTP model, the ATL_pre70 simulation shows little significant response in the Pacific around the equator, while the response in ATL_post70 is clear and significant in the 
central Pacific. It is worth noting that the impact of the EM over the Indian-Maritime Continent sector is also stronger in ATL_post70 than in ATL_pre70. Results from UCLA-AGCM show little response over the equatorial Pacific both at 200 and $925 \mathrm{hPa}$. Nevertheless, even though the upper level anomalies have negative values over the central equatorial Pacific (especially in ATL_pre70), they are consistent with anomalous divergence in the Northern Subtropical Pacific and anomalous convergence at the equator for the two simulations. UCLA velocity potential anomalies at $925 \mathrm{hPa}$ are weak in the equatorial Pacific, but also depict a tendency to anomalous surface divergence at the equator. Last row of Figures 2 and 3 show the differences between ATL_post70 and ATL_pre70 simulations in terms of ATL_post70 minus ATL_pre70 results for UCLA and ICTP experiments. Although the location of the surface divergence is different in each of the models, being west of $180 \mathrm{~W}$ for ICTP and east of $180 \mathrm{~W}$ for UCLA results, it is clear that the anomalous upper level convergence in the equatorial Pacific is stronger in ATL_post70 for both models, so is the anomalous surface divergence.

To quantify the robustness of the response along the different members of the simulations, we look at the anomalous velocity potential at $200 \mathrm{hPa}$ member by member of the ensemble (Figure 5 and Table 2). Results for ATL_post70 are more robust than those for ATL_pre70: for the UCLA model only two (five) out of ten simulations for ATL_post70 (ATL_pre70) show negative velocity potential anomalies in the upper atmosphere, were we would expect to find positive ones. For the ICTP results the robustness of ATL_post70 is even clearer: only seven (fourteen) out of sixty simulations for ATL_post70 (ATL_pre70) show negative anomalies in the upper atmosphere velocity potential. Thus, after the 1970's the response of the equatorial Pacific atmosphere to a warming in the equatorial Atlantic shows more robustness than before the 1970's.

Figure 6 shows the anomalous divergence at $200 \mathrm{hPa}$ for JAS for ATL_pre70 (first row), ATL_post70 (second row) and the differences between them (third row), for UCLA (left) and 
ICTP (right) results. In ATL_post70 the maximum divergence is located in the coast of South America, just in the place where the climatological divergence is maximum, while in ATL_pre70 the maximum anomalous divergence appears over the tropical Atlantic Ocean, and the anomalies of divergence over South America are weak and mostly negative. Thus, one would expect the effect of the EM to be stronger in ATL_post70 than in ATL_pre70.

The longitude-height sections of anomalous vertical velocity for both simulations, together with the differences between them, are shown in Figure 7 (UCLA, left column; ICTP right column). The ascending motions in the western Atlantic are a bit shifted to the west in ATL_post70 in the two models (Figure 7, second row); they are significantly stronger in ATL_pre70 between 0 and $60 \mathrm{~W}$, while ATL_post70 show more ascending motions around $60 \mathrm{~W}$ for the two models (Figure 7, third row). The latter simulations show continuous descending motions around the date line that, although weaker and shifted to the east, are also present in ATL pre70 (Figure 7, first row). The response in vertical velocity between $180 \mathrm{~W}-80 \mathrm{~W}$ is weak in ATL pre70 for both models, especially for ICTP. In the western Pacific, ATL_pre70 simulations show weak anomalous downward motions between 120E-180, except for a narrow band west of 180W in UCLA simulation (Figure 7, first row, left). The response for ATL_post70 simulations shows also anomalous downward motions overt the western Pacific (west of 180), stronger than in ATL $\_$pre70 for UCLA and ICTP models (figure 7, second row). The differences between simulations are clearly significant there (Figure 7, third row).

In order to assess the robustness of the responses, we have computed the anomalous vertical velocity averaged over the entire column and between $4 \mathrm{~S}-4 \mathrm{~N}$ and $170 \mathrm{~W}-190 \mathrm{~W}$ for each of the ensemble members of ATL_pre70 and ATL_post70, and for the ensemble mean (Figure 8 and Table 3). The results from UCLA model show that 5 out of 10 of the members of ATL pre70 show anomalous upward motions, were anomalous downwards would be expected if the Atlantic-Pacific connection were to exist; also the variability between members is higher than 
in ATL_post70, where only 1 out of 10 of the members show anomlous upward motions. For ICTP results, twentyone out of sixty members show upward motions in ATL_pre70, for only seventeen in ATL_post70. Thus, although the response in vertical velocity is noisy, especially for ICTP in both simulations, it is more robust in ATL_post70.

We have already seen that ATL_post70 has a stronger impact over the Indian and Maritime Continent sector (hereafter IMC) than ATL_pre70 and thus produces more convergence (Figure 3) which should produce stronger descending motions (Figure 7) over IMC at the equator; nevertheless, for both models the differences of vertical velocity averaged over $4 \mathrm{~S}-4 \mathrm{~N}$ between ATL_post70 and ATL_pre70 show negative values between $60 \mathrm{E}-120 \mathrm{E}$, that can be interpreted as a weakening of the anomalous downward motions in ATL_post70 with respect to ATL_pre70. To understand this, we represent in figure 9 the anomalies of velocity potential at $200 \mathrm{hPa}$ just in the tropical band. We analyze first the results from UCLA model: The anomalous convergence is stronger in ATL_post70 north of the equator (at the latitudes of the Indian subcontinent) and over the Maritime Continent, but is weaker at the equatorial band east of $100 \mathrm{E}$ (see also Figure 3, left column), which would explain the weaker anomalous downward motions in ATL_post70 than in ATL_pre70, and also the presence of a narrow band of anomalous upward motions east of $120 \mathrm{E}$ that reaches the surface only in ATL_post70 simulation. ICTP results also show stronger impact on the $200 \mathrm{hPa}$ vertical velocity over the Indian Ocean for ATL_post70 than for ATL_pre70 (Figure 9, right column); nevertheless, the spatial structure of the anomalous patterns shown in Figure 9 (right column) are quite different from those of UCLA simulations, showing anomalous equatorial convergence at the equator at around $90 \mathrm{E}$ and east of $180 \mathrm{~W}$, with a region of divergence between them. In ATL pre70 the divergence is located north of the equator at $90 \mathrm{E}$ and is tilted to the southeast and reaches the equator at approximately $100 \mathrm{E}$, with equatorial convergence to the southwest that would be responsible for anomalous downward motions centered in 120E. On the contrary, in 
ATL_post70 the anomalous convergence north of the equator extends from the Indian peninsula to Indochina, producing a secondary center of equatorial divergence and anomalous upward motions between 90E-120E. In summary, we can conclude that the effect of the EM over the Indian sector is stronger norh of the equator for the post70 pattern, but weaker over the equatorial band, favouring anomalous upward motions over the Maritime Continent west of $120 \mathrm{E}$.

Theoretically, the surface response to the EM in the central-western Pacific and in the Indian sector would be twofold. On the one hand, the EM produces anomalous descending motions over the Indian Sector that weakens the climatological ascending motions there, leading to anomalous surface divergence and thus weakening the trades blowing from the central Pacific into the Maritime Continent sector. On the other hand, the EM also produces descending motions in the central Pacific that would produce low-level divergence and a reinforcement of the trades between the central and the western Pacific.

Our results show that the ATL_post70 simulations have a significantly stronger effect in the anomalous vertical velocity at the equator near the date line than the ATL_pre70 ones. This impact seems to be produced by a westward extension of the anomalous upper level divergence due to the Atlantic SST anomalies that, in turn, forces anomalous upper level equatorial convergence (Figure 9). The downward movements induced by such circulation (Figure 7) would lead to a strengthening of the equatorial trade winds west of $180 \mathrm{~W}$, and a weakening of them to the east. Figure 10 shows the longitude by height anomalies of the zonal component of the wind averaged between $4 \mathrm{~S}-4 \mathrm{~N}$. The anomalous patterns depicted show the expected configuration, with stronger anomalous surface divergence around the date line in ATL post70 than in ATL_pre70 for both UCLA and ICTP models. Such anomalies of the zonal wind are reinforced by the changes in the impact of the EM over the Indian sector, that work against the anomalous descending motions east of $120 \mathrm{E}$ more in ATL_post70 than in ATL pre70, 
enhancing the divergence in the tropical Pacific in ATL_post70 and thus favouring the conditions for a development of a La Niña event there.

Nevertheless, when focusing at the surface signature of the zonal wind anomalies in Figure 10, one can see that, for UCLA model, neither ATL_pre70 nor ATL_post70 show any significant anomalous zonal wind in the central-western Pacific as a response to the Atlantic warming, which would be necessary to produce the piling up of water in the western Pacific and the triggering of Kelvin waves that would then cool the eastern Pacific basin.

In order to better understand the surface wind response of our experiments, Figure 11 depicts the zonal wind anomalies at the equator for the two experiments and the two models, as well as the difference of the response between periods. For ICTP model, the results are straightforward: the surface convergence over the western Atlantic is stronger in ATL post70 than in ATL_pre70, producing a stronger divergence east of the dateline and more negative anomalies of zonal wind. This result is in agreement with the theory above, and would lead to the cooling of the eastern Pacific if the model was coupled. It is worth noting that ATL_pre70 results also show negative anomalies of zonal wind in the equatorial Pacific, but the amplitude of such anomalies are weaker than for ATL_post70 (Figure 11, bottom right), and they are nonsignificant (Figure 10).

Results of UCLA model are not that clear. We can see the reinforcement of the surface convergence in the western Atlantic, but the response of the equatorial surface wind anomalies in the Pacific is weak and shows positive, although not significant (Figure 10) anomalous values along the whole basin for both ATL_pre70 and ATL_post70. Although the differences between periods depict anomalous divergence near the dateline (Figure 11, bottom left), pointing to a situation more favourable for an Atlantic-Pacific connection in ATL_post70 than 
in ATL_pre70, our results suggest that UCLA model wouldn't produce a La Niña-type response if coupled.

The inconsistency between UCLA and ICTP results in terms of anomalous zonal wind deserves a deeper investigation. From Figure 7, it is clear that the response over the Indian and Maritime Continent is quite different in both models, UCLA shows anomalous descendant motions between $60 \mathrm{E}$ and $180 \mathrm{E}$ in both simulations, except for the presence of anomalous upward motions in a narrow band east of 120E. On the contrary, for ICTP the anomalous upward motions east of $120 \mathrm{E}$ are stronger than the UCLA ones, and the downward motions in the Indian sector are confined to a narrow band around 60E. The stronger downward motions over the Indian Ocean in UCLA could be responsible of the easterly anomalies of the equatorial zonal wind east of aproximately 100E in ATL_pre70 and ATL_post70. Thus, our results suggest that the response of the equatorial Pacific to an Atlantic EM is model dependent, and that this dependency relies in the way in which the model simulates the impact of the Atlantic EM in the Indian sector. Although that impact in both models acts in favour of more anomalous upward motions in ATL_post70 than in ATL_pre70, the actual sign of the anomalus vertical motions over the IMC plays a substantial role in the equatorial Pacific response. It is worth noting that ICTP results are more in agreement with the observed response to an EM (Polo et al., 2015) than UCLA ones.

Previous studies have shown that not all the coupled models of the CMIP-5 experiment are able to simulate the Atlantic-Pacific connection (Ott et al., 2015). According to our results, the response of the models in the IMC sector could be the key factor controling the appearance of not of the connection in models.

\section{Summary and Conclusions:}


The differences in the spatial configuration of the EM before and after the 1970's seem to have an impact in the atmospheric response to the EM over the tropical Pacific Ocean, that appears to be driven by changes in the tropical circulation. The stronger impact found for the post70 EM shed light about the influence that the location of the equatorial anomalous heating can produce over the adjacent oceans.

Results shown here illustrate that, after the 1970's, the EM is more able to modify the atmospheric circulation in the central Pacific through changes in the Walker circulation in the Atlantic-Pacific region, producing anomalous downward movements around the date line. Also, the impact of the EM on the equatorial Indian sector favours the anomalous ascending motions east of $120 \mathrm{E}$ more after the 1970's than before. Both effects added together lead to a reinforcement of the easterly anomalies of the trade winds between $120 \mathrm{E}-180 \mathrm{~W}$, stronger after the 1970's than before. This reinforcement would produce the piling up of water there and could favour the development of a La Niña event in the Pacific, following the processes described in Polo et al (2015) and in agreement with a simple recharge oscillator model (Jin, 1997).

Our results also show that the actual response of the trade winds in the western and central Pacific can be highly dependent on the model used, and that the key factor controling such response seems to be the way in which the model simulate the impact of the EM in the IMC sector.

In this way, we can conclude that the change of the impact of the EM in both the AtlanticPacific walker circulation and the Indian subcontinent north of the equator is clear, being such impacts stronger for the EM that shows anomalies covering the whole equatorial basin. Nevertheless, the impact over the IMC at the equator is different between models, and this differece is what would determine the success of the model in the simulation or not of the 
surface wind conditions necessary for the development of an ENSO event as a response to an Atlantic EM.

Our results imply that the different configuration of the EM before and after the 1970's has an impact in the tropical atmospheric circulation forced by such mode. Nevertheless, a question arises due to the fact that, apart from the effect of the EM itself, there are also decadal differences in the background state of the global oceans before and after the 1970's. One could wonder if such differences in the background state of the global SST could play a role in the observed tropical response to the EM before and after the 1970's and if the impact of the different background state would work against or in favour of the impact produced by the changes in the configuration of the EM. A second question would be if the changes in the background state and in the EM are related and, if so, how is the nature of such relationship. All these questions will be the focus of future works.

\section{Aknowledgements}

The research leading to these results has received funding from the European Union Seventh Framework Programme (FP7/2007-2013) under Grant Agreement No. 603521 (PREFACE project), and by the Spanish project CGL2012-38923-C02-01. The authors thank two anonymous reviewers for their constructive suggestions and comments that have improved this work, as well as the editor for his help along the whole process of publication of the paper.

\section{References}

Bjerknes J (1969) Atmospheric teleconnections from the Equatorial Pacific. Month Weather Rev 97:163-172

Cassou C, Desert C, Terray L, Hurrell JW, Drévillon M (2004) Summer sea surface temperature conditions in the North Atlantic and their impact upon the atmospheric circulation in early winter. J Clim 17: 3349-3363.

Ding H, Keenlyside NS, Latif M (2011) Impact of the Equatorial Atlantic on the El Niño Southern Oscillation. Clim Dyn doi: 10.1007/s00382-011-1097-y. 
García-Serrano J, Losada T, Rodríguez-Fonseca B, Polo I (2008) Tropical Atlantic variability modes (1979-2001). Part II: timeevolving atmospheric circulation related to SST-forced. J Clim 21: 6476-6497.

Giannini A, Saravanan R, Chan P (2004) The preconditioning role of Tropical Atlantic variability in the development of the ENSO teleconnection: implications for the prediction of Nordeste rainfall. Clim Dyn 22:839-855

Gill AE (1980) Some simple solutions for heat-induced tropical circulation. Quat J R Met Soc 106: 447-462.

Janicot S (1992) Spatiotemporal variability of West African rainfall. Part II: associated surface and airmass characteristics. J Clim 5:499-511

Janicot S, Harzallah A, Fontaine B, Moron V (1998) West African Monsoon dynamics and Eastern Equatorial Atlantic and Pacific SST anomalies (1970-88). J Clim 11:1874-1882

Jansen MF, Dommenget D, Keenlyside NS (2009) Tropical Atmosphere-Ocean interactions in a conceptual framework. J Clim 22:550-567

Jin FF, (1997) An equatorial recharge paradigm for ENSO I: Conceptual Model, J. Atmos. Sci., 54:811-829.

Keenlyside NS, Latif M (2007) Understanding Equatorial Atlantic interannual variability. J Clim 20:131-142

Keenlyside NS, Ding H, Latif M (2013) Potential of equatorial Atlantic variability to enhance El Niño prediction. Geophys Res Lett 40:2278-2283. doi:10.1002/grl.50362

Knight JR, Allan RJ, Folland CK, Vellinga M, Mann ME (2005) A signature of persistent natural thermohaline circulation cycles in observed climate. Geophys Res Lett 32. doi:10.1029/2005GL024233

Kucharski F, Bracco A, Yoo JH, Molteni F (2007) Low-frequency variability of the Indian Monsoon-ENSO relationship and the Tropical Atlantic: The "Weakening" of the 1980s and 1990s. J Clim 20:4255-4266

Kucharski F, Bracco A, Yoo JH, Molteni F (2008) Atlantic forced component of the Indian monsoon interannual variability. Geophys Res Lett 35:L04706. doi:10.1029/2007GL033037

Kucharski F, Bracco A, Yoo JH, Molteni F (2009) A Gill-Matsuno-type mechanism explains the tropical Atlantic influence on African and Indian monsoon rainfall. Q J R Meteorol Soc 135:569-579

López-Parages J, Rodríguez-Fonseca B (2012) Multidecadal modulation of El Niño influence on the Euro-Mediterranean rainfall. Geophys Res Lett 39:L02704. doi: 10.1029/2011GL050049

Losada T, Rodríguez-Fonseca B, Janicot S, Gervois S, Chauvin F, Ruti P (2010a) A multimodel approach to the Atlantic Equatorial Mode: impact on the West African monsoon. Clim Dyn 35:29-43

Losada T, Rodríguez-Fonseca B, Polo I, Janicot S, Gervois S, Chauvin F, Ruti P (2010b) Tropical response to the Atlantic Equatorial Mode: AGCM multimodel approach. Clim Dyn $35: 45-52$ 
Losada T, Rodríguez-Fonseca B, Mohino E, Bader J, Janicot S, Mechoso CR (2012a) Tropical SST and Sahel rainfall: A non-stationary relationship. Geophys Res Lett 39: L12705. doi: 10.1029/2012GL052423

Losada T, Rodríguez-Fonseca B, Kucharski F (2012b) Tropical influence on the summer Mediterranean climate. Atmos Sci Lett 13:36-42

Martín-Rey M, Polo I, Rodríguez-Fonseca B, Kucharski F (2012) Changes in the interannual variability of the Tropical Pacific related to the equatorial Atlantic. Sci Mar, 76:105-116. doi: 103989/scimar.03610.19a

Martín-Rey M, Polo I, Rodríguez-Fonseca B, Polo I, Kucharski F (2014) On the AtlanticPacific Niños connection: a multidecadal modulated mode. Clim. Dyn. 43: 3163-3178.DOI: $10.1007 / \mathrm{s} 00382-014-2305-3$

Mechoso CR, Yu JY, Arakawa A (2000) A coupled GCM pilgrimage: from climate catastrophe to ENSO simulations. In: Randall DA (ed) General Circulation Model Development: past, present and future. Proceedings of a symposium in honor of Professor Akio Arakawa. Academic, New York, pp 539-575.

Mohino E, Rodríguez-Fonseca B, Losada T, Gervois S, Janicot S, Bader J, Ruti P, Chauvin F (2011) Changes in the intereannual SST-forced signals on West African rainfall. AGCM intercomparison. Clim Dyn 37:1707-1725

Nnamchi HC, Li J, Anyadike RNC (2011) Does a dipole mode really exist in the South Atlantic Ocean? J Geophys Res 116:D15104. doi:10.1029/2010JD015579

Ott I, Romberg K, Jacobeit J (2015) Teleconnections of the tropical Atlantic and Pacific Oceans in a CMIP5 model ensemble. Clim Dyn 44:3043-3055

Polo I, Martin-Rey M, Rodriguez-Fonseca B, Kucharski F, Mechoso CR (2015) Processes in the Pacific La Niña onset triggered by the Atlantic Niño. Clim. Dyn. 44: 115-131

Polo I, Rodríguez-Fonseca B, Losada T, García-Serrano J (2008) Tropical Atlantic variability modes (1979-2002). Part I: Time-evolving SST modes related to West African precipitation. J Clim 21:6457-6475

Richter I, Mechoso CR, Robertson AW(2008), What determines the position and intensity of the south Atlantic anticyclone in Austral Winter? An AGCM study. J. Clim 21: 214-229.

Richter I, Behera SK, Masumoto Y, Taguchi B, Sasaki H, Yamagata T (2012) Multiple causes of interannual sea surface temperature variability in the equatorial Atlantic Ocean. Nature Geos 6: 43-47. doi: 10.1038/ngeo1660

Rodriguez-Fonseca B, Polo I, Garcia-Serrano J, Losada T, Mohino E, Mechoso CR, Kucharski F (2009) Are Atlantic Ninos enhancing Pacific ENSO events in recent decades? Geophys Res Lett 36:L20705. doi:10.1029/2009GL040048

Rowell DP, Folland CK, Maskel K, Owen JA, Ward MN (1995), Variability of the summer rainfall over tropical North Africa (1906-92): Observations and modeling. Quat. J. Roy. Meteor. Soc., 121: 669-704. Doi: 10.1002/qj.49712152311.

Ruiz-Barradas A, Carton JA, Nigam S (2000) Structure of interannual-to-decadal climate variability in the Tropical Atlantic sector. J. Clim 13: 3285-3297. 
Smith, T. M., R. W. Reynolds, T. C. Peterson, and J. Lawrimore (2008), Improvements to NOAA's historical merged land-ocean surface temperatura analysis (1880-2006), J. Clim., 21, 2283-2296, doi:10.1175/2007JCLI2100.1

Stephenson, D. B., V. Pavan, and R. Bojariu (2000), Is the North Atlantic Oscillation a random walk?, Int. J. Climatol., 20, 1-18, doi:10.1002/(SICI)1097-0088(200001)20:1<1::AIDJOC456>3.0.CO;2-P.

Vizy EK, Cook KH (2002) Development and application of a mesoscale climate model for the tropics: influence of sea surface temperature anomalies on the West African monsoon. $\mathrm{J}$ Geophys Res 107(D3). doi:10.1029/2001JD000686

von Storch H, Zwiers FW (1999) Statistical analysis in climate research. Cambridge University Press, New York. ISBN 0521450713

Wang C (2006) An overlooked feature of tropical climate: Inter-Pacific-Atlantic variability. Geophys Res Lett 33:L12702. doi: 10.1029/2006GL026324

Wang C, Kucharski F, Barimalala R, Bracco A (2009) Teleconnections of the Tropical Atlantic to the Tropical Indian and Pacific Oceans: a review of recent findings. Spec Issue Meteorol Zeitschrift 18. doi:10.1127/0941-2948/2009/0394

Xie, S-P, Carton JA (2004) Tropical Atlantic variability: Patterns, mechanisms, and impacts. Earth Climate: The Ocean-Atmosphere Interaction, C. Wang et al., Eds., Geophys. Monogr., Vol. 147, Amer. Geophys. Union, 121-142.

Zebiak SE (1993) Air-sea interaction in the equatorial Atlantic region. J Clim 6:1567- 1586

Zhang Y, Wallace JM, Battisti DS (1997) ENSO-like interdecadal variability:1900-93. J Clim 10:1004-1020

Tables:

\begin{tabular}{|l|l|l|}
\hline & \multicolumn{1}{|c|}{$\mathbf{5 0 6 9}$} & $\mathbf{7 5 9 4}$ \\
\hline Positive Atl3 years & $1951,1963,1968$ & $1979,1981,1984,1988$ \\
\hline Negative Atl3 years & $1950,1958,1964,1967,1969$ & $1976,1982,1983,1986,1992$ \\
\hline
\end{tabular}

Table 1: Years used for the computation of the boundary conditions used in the AGCM sensitivity experiments.

\begin{tabular}{|l|c|c|c|c|}
\hline & \multicolumn{2}{|c|}{$\begin{array}{c}\text { Number of members with positive } \\
\text { anomalies }\end{array}$} & $\begin{array}{c}\text { Number of members with negative } \\
\text { anomalies }\end{array}$ \\
\cline { 2 - 5 } & UCLA & ICTP & UCLA & ICTP \\
\hline vpot 200 ATL_pre70 & 5 & 46 & 5 & 14 \\
\hline vpot 200 ATL_post70 & 8 & 53 & 2 & 7 \\
\hline
\end{tabular}


Table 2: Number of members of each simulation that show positive (green) and negative (red) sign of the anomaly of JAS velocity potential at 200 and $925 \mathrm{hPa}$, and between 4S-4N and 170W-190W.

\begin{tabular}{|l|c|c|c|c|}
\hline \multirow{2}{*}{} & \multicolumn{2}{|c|}{$\begin{array}{c}\text { Number of members with } \\
\text { positive anomalies }\end{array}$} & \multicolumn{2}{|c|}{$\begin{array}{c}\text { Number of members with } \\
\text { negative anomalies }\end{array}$} \\
\cline { 2 - 5 } & UCLA & ICTP & UCLA & ICTP \\
\hline w 5069 & 5 & 39 & 5 & 17 \\
\hline w 7594 & 9 & 43 & 1 & 17 \\
\hline
\end{tabular}

Table 3: Number of members of each simulation that show the positive (green) and negative (red) sign of the anomaly of JAS vertical velocity averaged over the entire column (between 925 and $100 \mathrm{hPa}$ ) and between $4 \mathrm{~S}-4 \mathrm{~N}$ and $170 \mathrm{~W}-190 \mathrm{~W}$.

\section{Figure captions:}

Figure 1: JAS SST anomalies $\left(^{\circ}\right)$ corresponding to the Equatorial Mode for ATL pre70 (left top) and ATL_post70 (left bottom); and the 90\% significant differences between them with a Monte Carlo method of 500 permutations (right).

Figure 2: JAS anomalous streamfunction $\left(10^{6} \mathrm{~m}^{2} \mathrm{~s}^{-2}\right)$ at $200 \mathrm{hPa}$ for ATL pre70 (first row), ATL_post70 (second row) simulations and the difference between them (third row) for UCLA (left) and ICTP (right) models. Dots denote those regions where the anomalies are significant at a $95 \%$ confidence level.

Figure 3: JAS anomalous velocity potential $\left(10^{6} \mathrm{~m}^{2} \mathrm{~s}^{-2}\right)$ at $200 \mathrm{hPa}$ for ATL pre70 (first row), ATL_post70 (second row) simulations and the difference between them (third row) for UCLA (left) and ICTP (right) models. Dots denote those regions where the anomalies are significant at a $95 \%$ confidence level.

Figure 4: JAS anomalous velocity potential $\left(10^{6} \mathrm{~m}^{2} \mathrm{~s}^{-2}\right)$ at $925 \mathrm{hPa}$ for ATL pre70 (first row), ATL_post70 (second row) simulations and the difference between them (third row) for UCLA (left) and ICTP (right) models. Dots denote those regions where the anomalies are significant at a $95 \%$ confidence level.

Figure 5: Anomalous JAS $200 \mathrm{hPa}$ velocity potential $\left(10^{6} \mathrm{~m}^{2} \mathrm{~s}^{-2}\right)$ averaged between $4 \mathrm{~S}-4 \mathrm{~N}$ and $170 \mathrm{~W}-190 \mathrm{~W}$ for each of the members of the ensemble of UCLA (top) and ICTP (bottom) (1 to 10 and 1 to 60 respectively) and for the ensemble mean (11 and 61) of ATL pre70 (left) and ATL_post70 (right) simulations.

Figure 6: JAS anomalous divergence $\left(\mathrm{s}^{-1}\right)$ at $200 \mathrm{hPa}$ for ATL pre70 (first row) and ATL_post70 (second row) simulations and the difference between them (third row) for UCLA (left) and ICTP (right) models. Dots denote those regions where the anomalies are significant at a $95 \%$ confidence level. 
Figure 7: Longitude by height sections of anomalous JAS vertical velocity (100 $\left.\mathrm{Pa} \mathrm{s}{ }^{-1}\right)$ averaged between 4S-4N for ATL_pre70 (first row) and ATL_post70 (second row) simulations and the difference between them (third row) for UCLA (left) and ICTP (right) models. Gray lines denote those regions where the anomalies are significant at a 95\% confidence level.

Figure 8: Anomalous JAS vertical velocity averaged over the entire column and between 4S$4 \mathrm{~N}$ and $170 \mathrm{~W}-190 \mathrm{~W}$ for each of the members of the ensemble of ICTP (left) and UCLA (right) ( 1 to 10 and 1 to 60 respectively) and for the ensemble mean (11 and 61) of ATL pre70 (top) and ATL_post70 (bottom) simulations.

Figure 9: JAS anomalous velocity potential $\left(10^{6} \mathrm{~m}^{2} \mathrm{~s}^{-2}\right)$ at $200 \mathrm{hPa}$ for ATL pre70 (first row) and ATL_post70 (second row) simulations for UCLA (left) and ICTP (right) models, just in the tropical band. Dots denote those regions where the anomalies are significant at a $95 \%$ confidence level.

Figure 10: Longitude by height section of anomalous JAS zonal wind ( $\mathrm{m} / \mathrm{s})$ averaged between 4S-4N for ATL_pre70 (first row) and ATL_post70 (second row) simulations and the difference between them (third row) for UCLA (left) and ICTP (right) models. Gray lines denote those regions where the anomalies are significant at a 95\% confidence level.

Figure 11: Longitude section of anomalous JAS zonal-averaged zonal wind $(\mathrm{m} / \mathrm{s})$ at the equator for ATL_pre70 (first row) and ATL_post70 (second row) simulations and the difference between them (third row) for UCLA (left) and ICTP (right) models. 

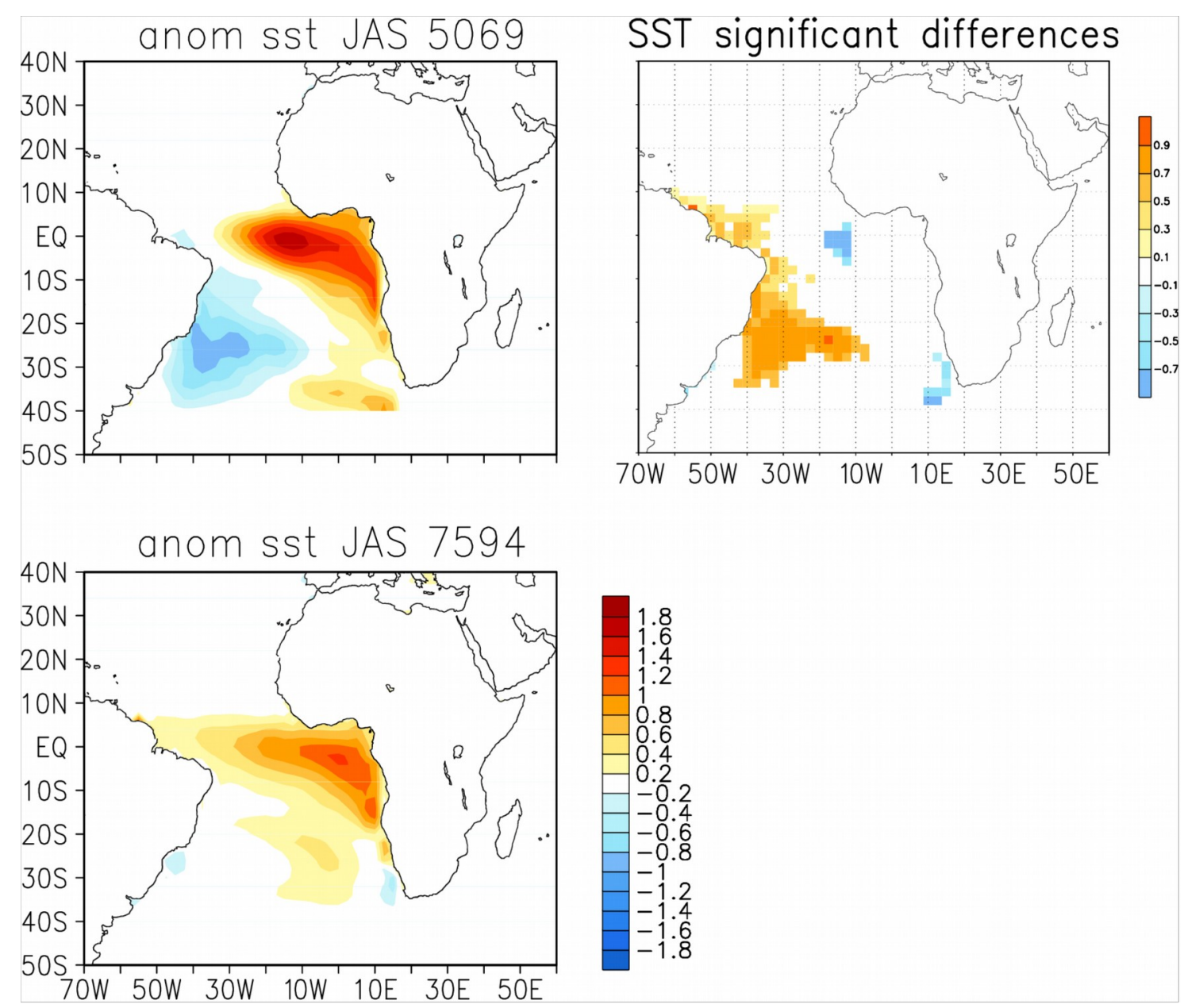

Figure 1: JAS SST anomalies $\left({ }^{\circ}\right)$ corresponding to the Equatorial Mode for ATL pre70 (left top) and ATL_post70 (left bottom); and the 90\% significant differences between them with a Monte Carlo method of 500 permutations (right). 

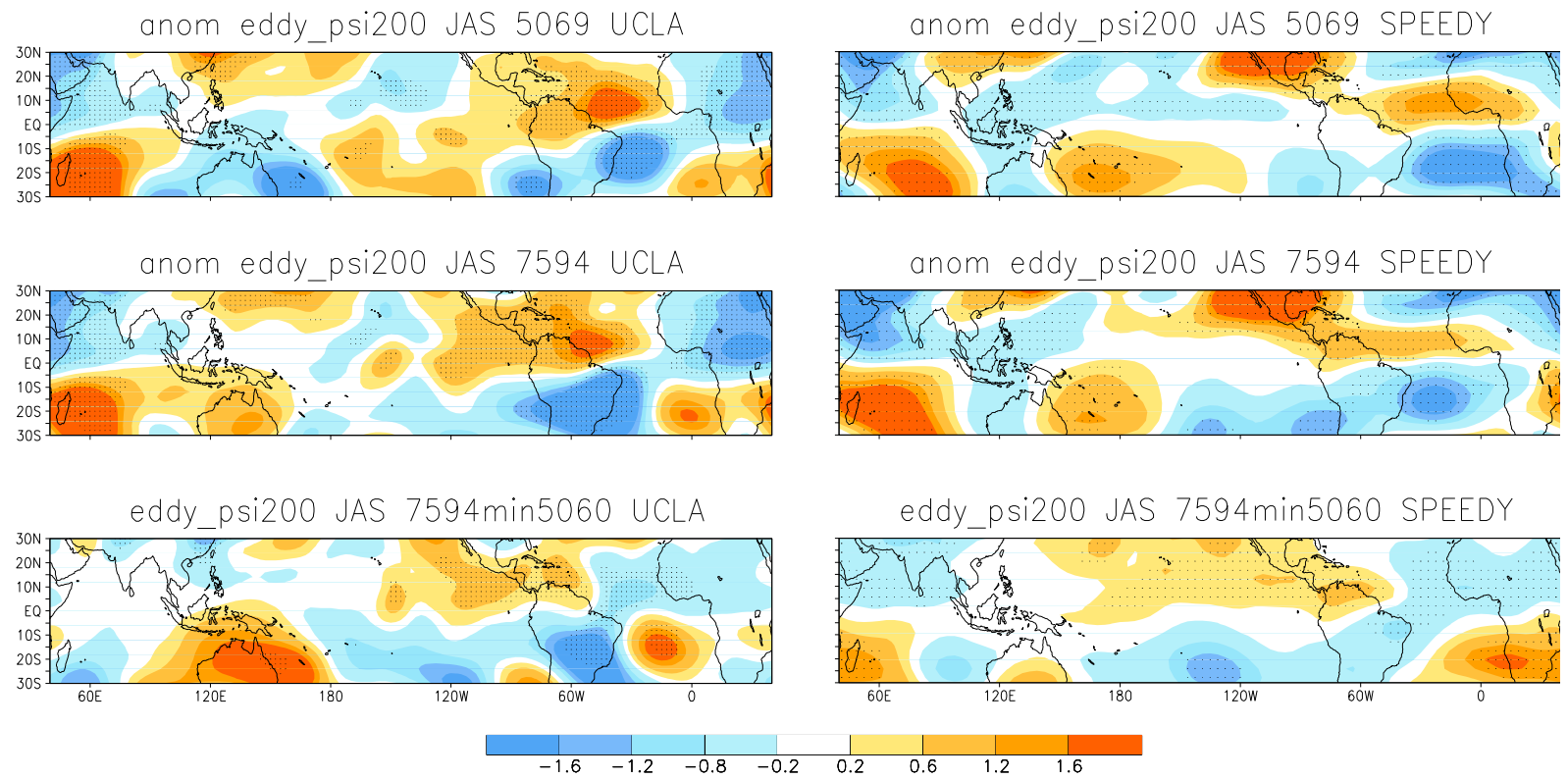

Figure 2: JAS anomalous streamfunction $\left(10^{6} \mathrm{~m}^{2} \mathrm{~s}^{-2}\right)$ at $200 \mathrm{hPa}$ for ATL pre70 (first row), ATL_post70 (second row) simulations and the difference between them (third row) for UCLA (left) and ICTP (right) models. Dots denote those regions where the anomalies are significant at a $95 \%$ confidence level. 
anom vpot200 JAS 5069 UCLA

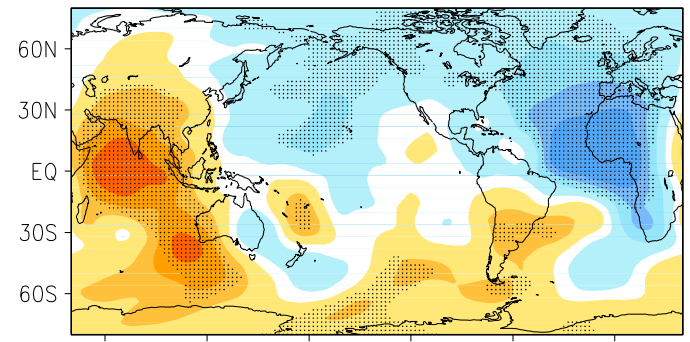

anom vpot200 JAS 7594 UCLA

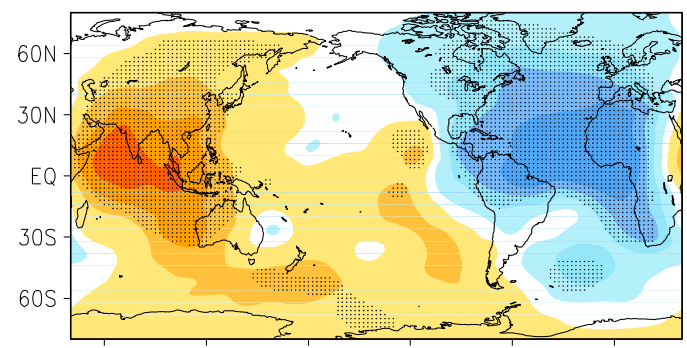

vpot200 JAS 7594 min5060 UCLA

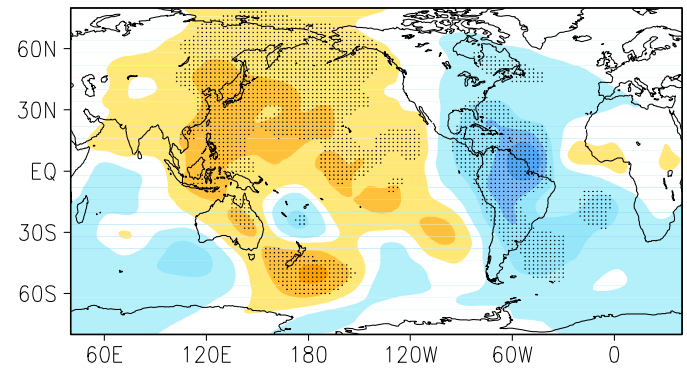

anom vpot200 JAS 5069 SPEEDY

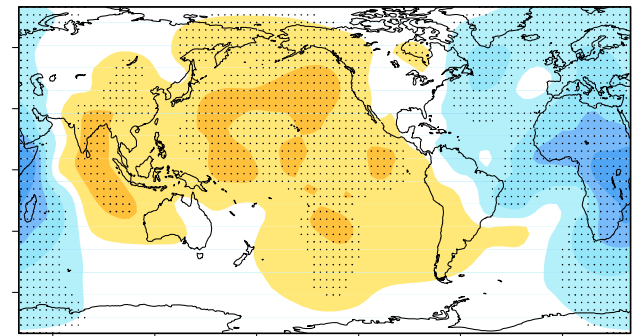

anom vpot200 JAS 7594 SPEEDY

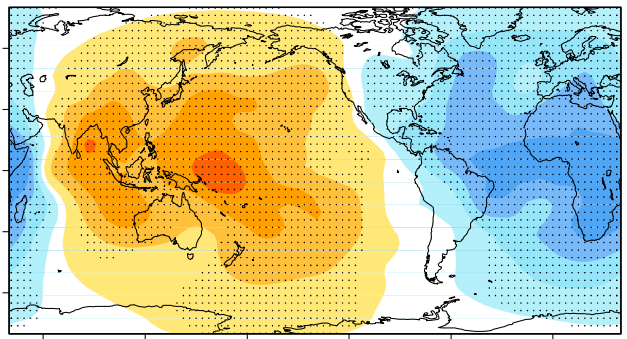

vpot200 JAS 7594 min5060 SPEEDY

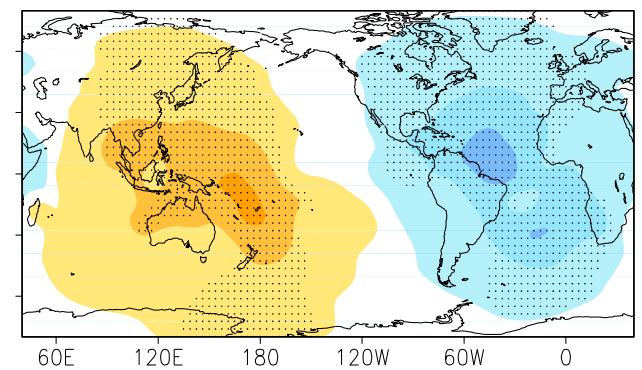

Figure 3: JAS anomalous velocity potential $\left(10^{6} \mathrm{~m}^{2} \mathrm{~s}^{-2}\right)$ at $200 \mathrm{hPa}$ for ATL_pre70 (first row), ATL_post70 (second row) simulations and the difference between them (third row) for UCLA (left) and ICTP (right) models. Dots denote those regions where the anomalies are significant at a $95 \%$ confidence level. 
anom vpot925 JAS 5069 UCLA

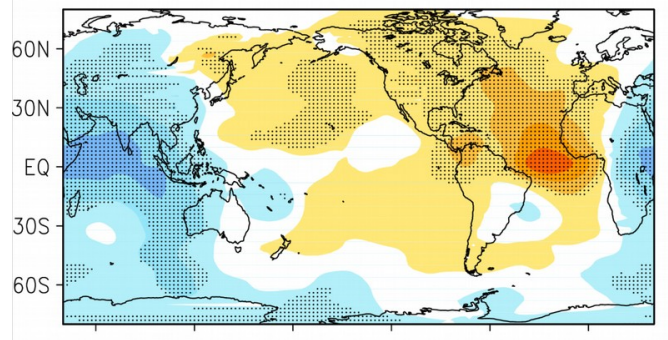

anom vpot925 JAS 7594 UCLA

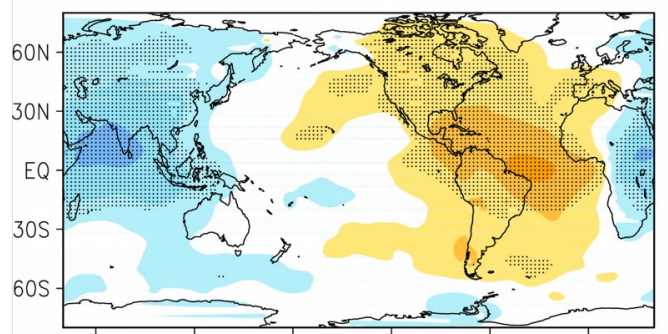

vpot925 JAS 7594 min5060 UCLA

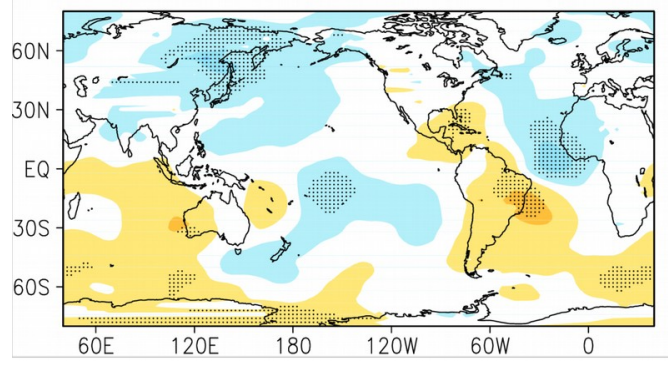

anom vpot925 JAS 5069 SPEEDY

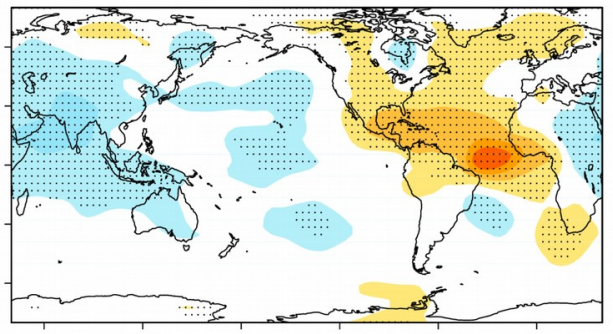

anom vpot925 JAS 7594 SPEEDY
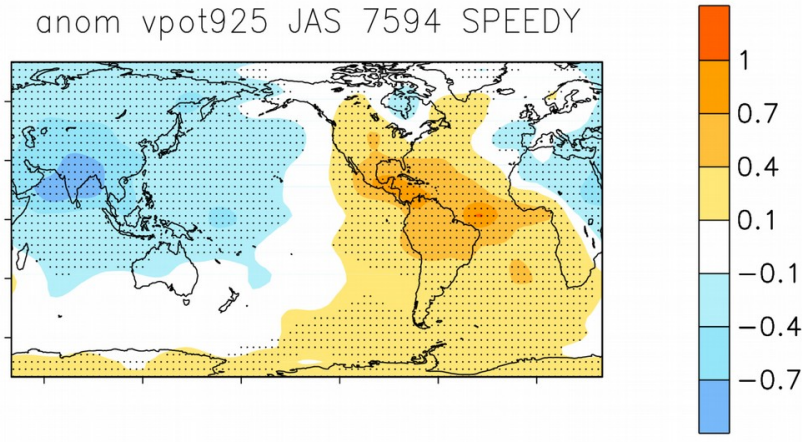

vpot925 JAS $7594 \min 5060$ SPEEDY

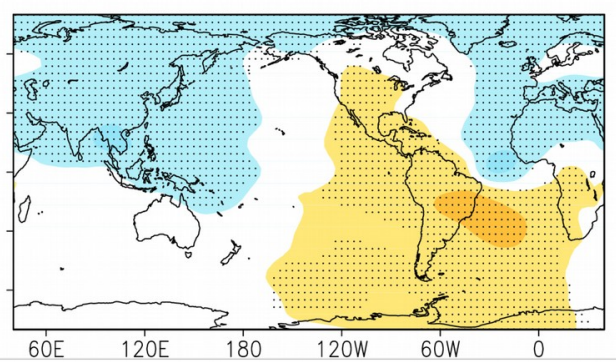

Figure 4: JAS anomalous velocity potential $\left(10^{6} \mathrm{~m}^{2} \mathrm{~s}^{-2}\right)$ at $925 \mathrm{hPa}$ for ATL pre70 (first row), ATL_post70 (second row) simulations and the difference between them (third row) for UCLA (left) and ICTP (right) models. Dots denote those regions where the anomalies are significant at a $95 \%$ confidence level. 

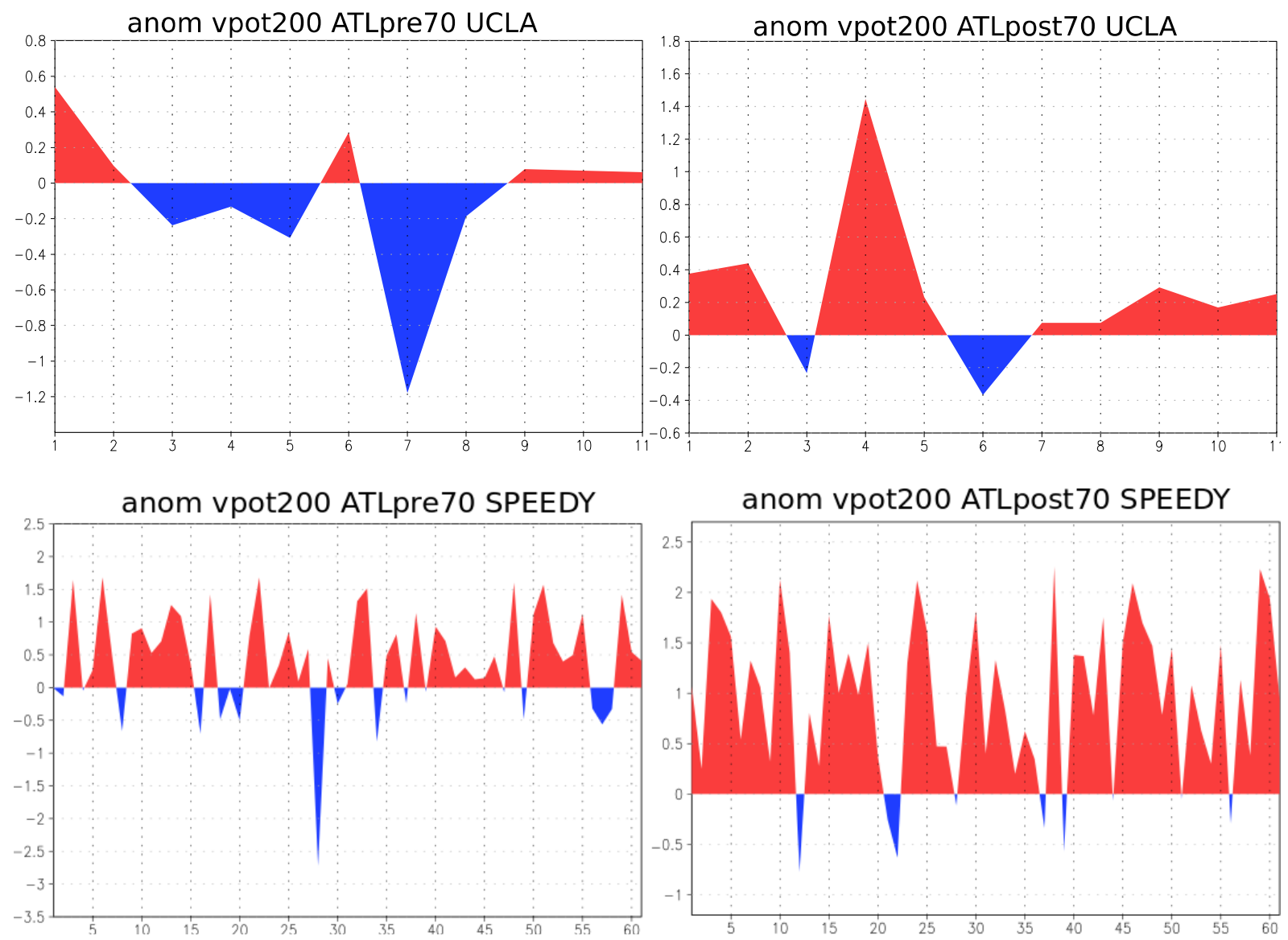

Figure 5: Anomalous JAS $200 \mathrm{hPa}$ velocity potential $\left(10^{6} \mathrm{~m}^{2} \mathrm{~s}^{-2}\right)$ averaged between $4 \mathrm{~S}-4 \mathrm{~N}$ and $170 \mathrm{~W}-190 \mathrm{~W}$ for each of the members of the ensemble of UCLA (top) and ICTP (bottom) (1 to 10 and 1 to 60 respectively) and for the ensemble mean (11 and 61) of ATL pre70 (left) and ATL_post70 (right) simulations. 
anom div 200 JAS 5069 UCLA

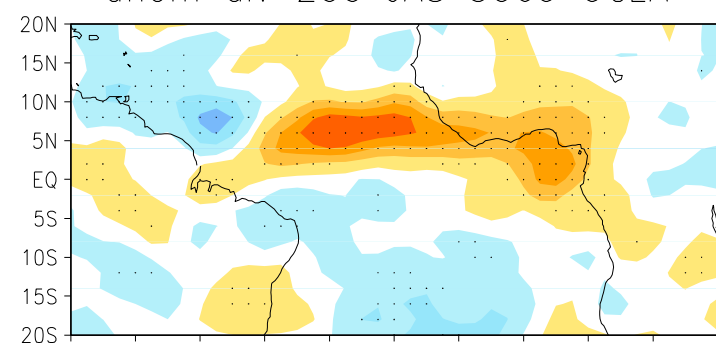

anom div 200 JAS 7594 UCLA

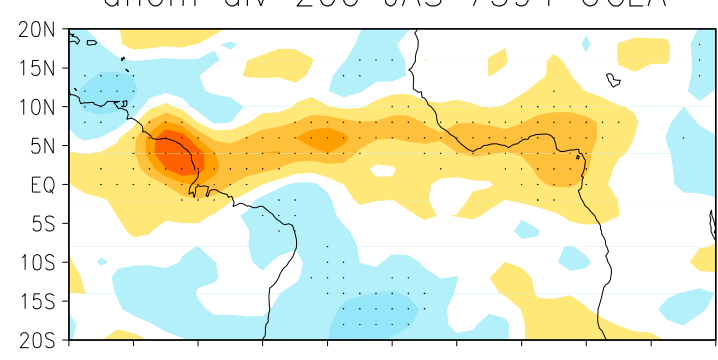

div 200 JAS 7594 min5060 UCLA

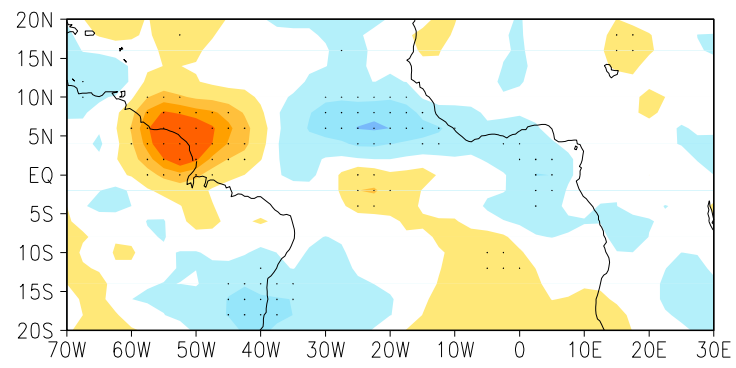

anom div 200 JAS 5069 SPEEDY

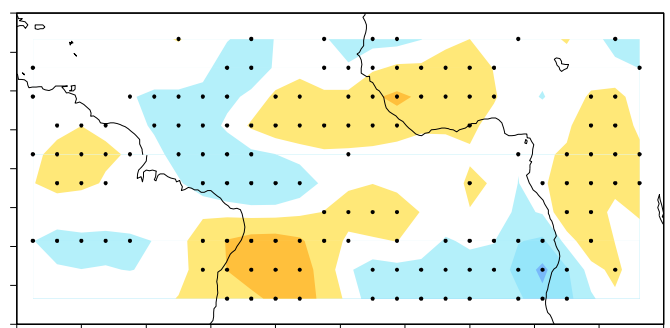

anom div 200 JAS 7594 SPEEDY
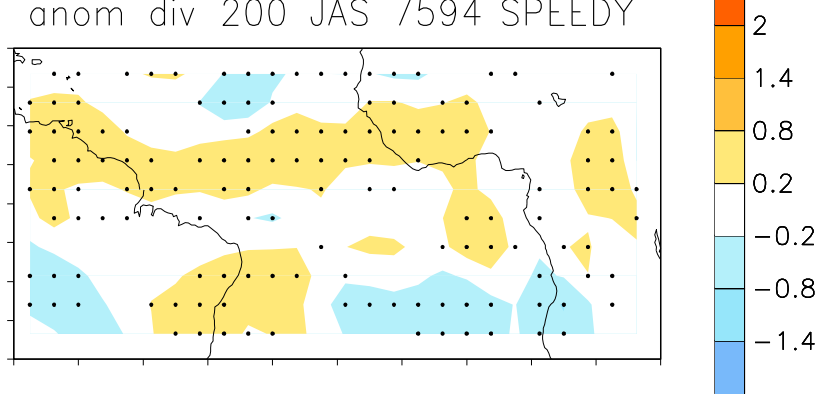

div 200 JAS 7594 min5060 SPEEDY

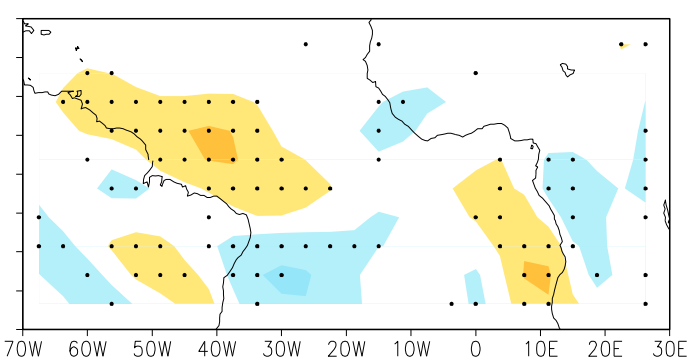

Figure 6: JAS anomalous divergence $\left(\mathrm{s}^{-1}\right)$ at $200 \mathrm{hPa}$ for ATL pre70 (first row) and ATL_post70 (second row) simulations and the difference between them (third row) for UCLA (left) and ICTP (right) models. Dots denote those regions where the anomalies are significant at a $95 \%$ confidence level. 
anom w JAS 5069 UCLA

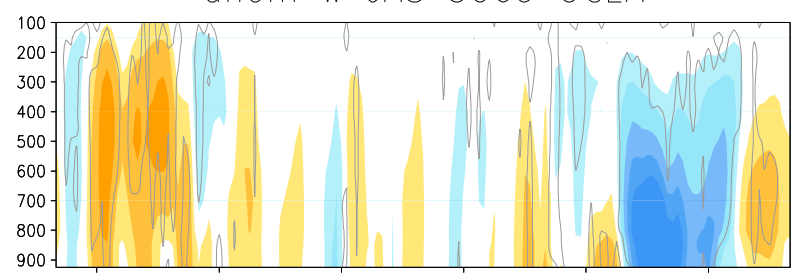

anom w JAS 7594 UCLA

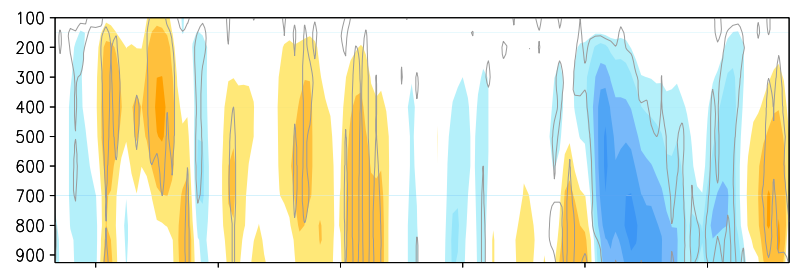

W JAS $7594 \mathrm{~min} 5060$ UCLA

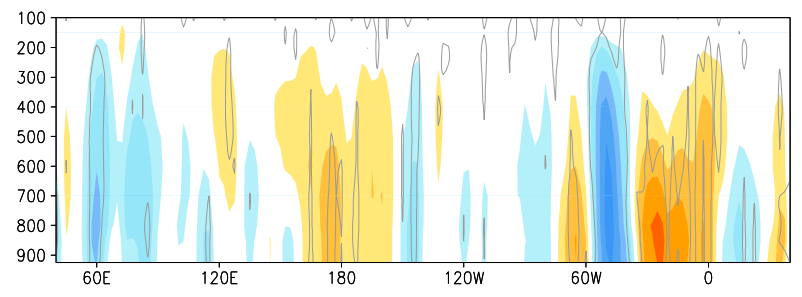

anom w JAS 5069 SPEEDY

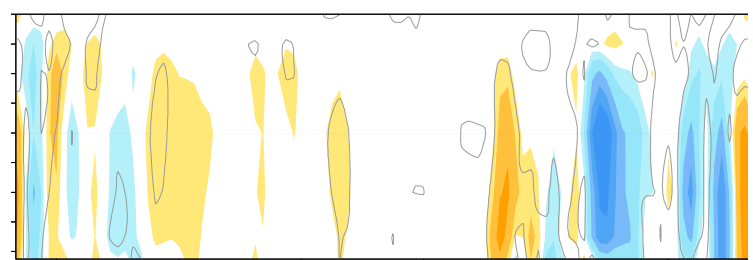

anom w JAS 7594 SPEEDY

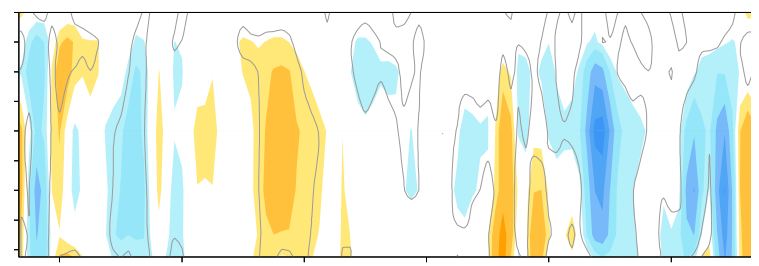

W JAS 7594 min5060 SPEEDY

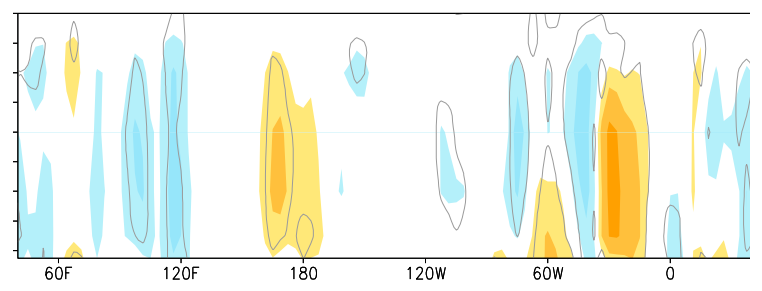

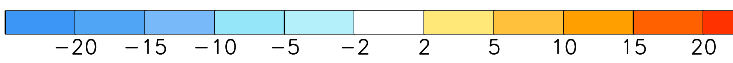

Figure 7: Longitude by height sections of anomalous JAS vertical velocity (100 $\left.\mathrm{Pa} \mathrm{s}{ }^{-1}\right)$ averaged between 4S-4N for ATL_pre70 (first row) and ATL_post70 (second row) simulations and the difference between them (third row) for UCLA (left) and ICTP (right) models. Gray lines denote those regions where the anomalies are significant at a 95\% confidence level. 

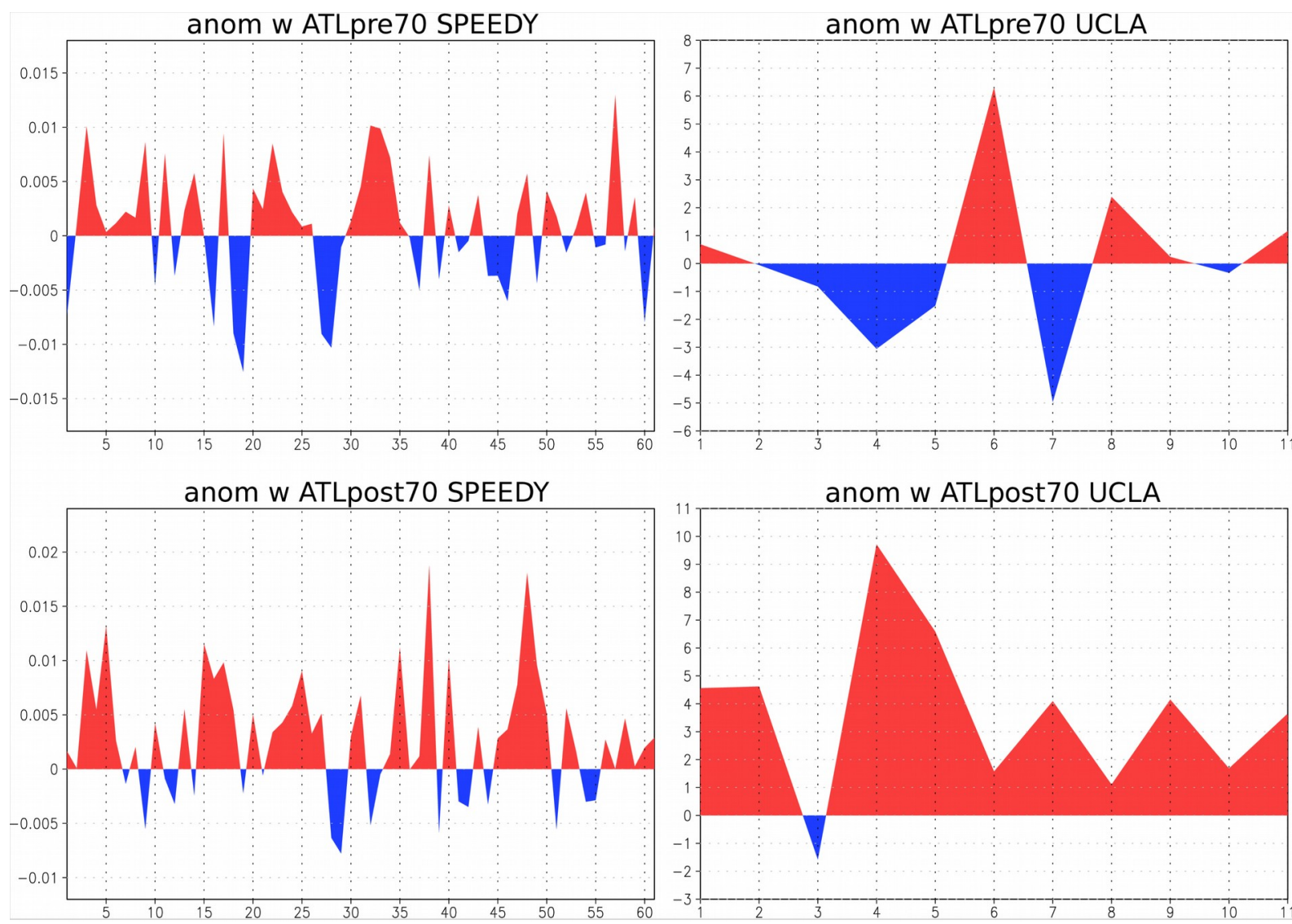

Figure 8: Anomalous JAS vertical velocity averaged over the entire column and between 4S$4 \mathrm{~N}$ and $170 \mathrm{~W}-190 \mathrm{~W}$ for each of the members of the ensemble of ICTP (left) and UCLA (right) ( 1 to 10 and 1 to 60 respectively) and for the ensemble mean (11 and 61) of ATL pre70 (top) and ATL_post70 (bottom) simulations.

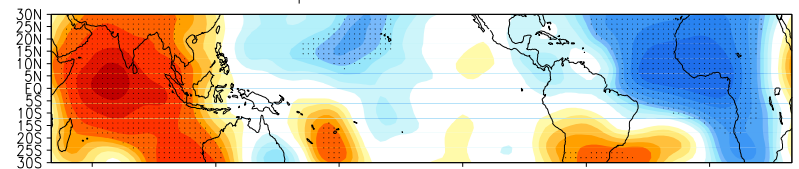

anom vpot200 JAS 5069 SPEEDY

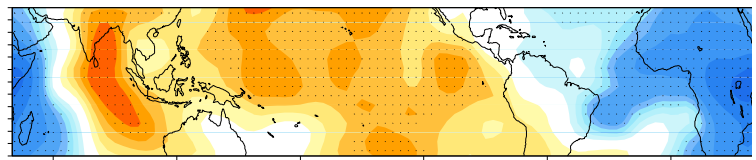

anom vpot200 JAS 7594 UCLA

anom vpot200 JAS 7594 SPEEDY

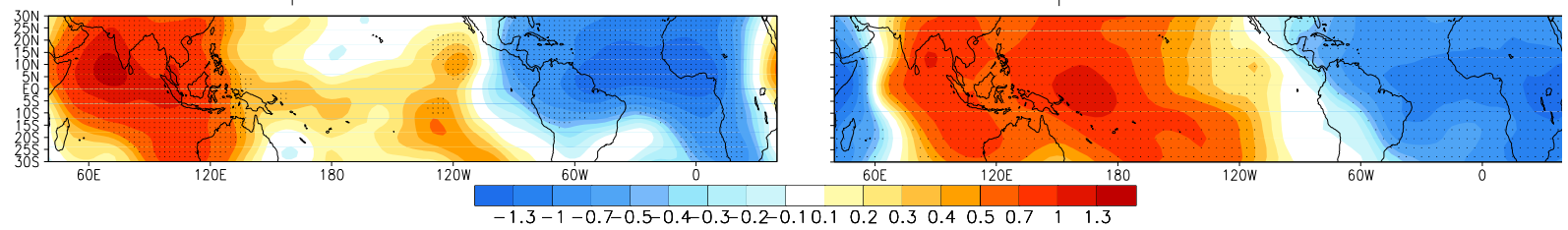


Figure 9: JAS anomalous velocity potential $\left(10^{6} \mathrm{~m}^{2} \mathrm{~s}^{-2}\right)$ at $200 \mathrm{hPa}$ for ATL pre70 (first row) and ATL_post70 (second row) simulations for UCLA (left) and ICTP (right) models, just in the tropical band. Dots denote those regions where the anomalies are significant at a $95 \%$ confidence level.
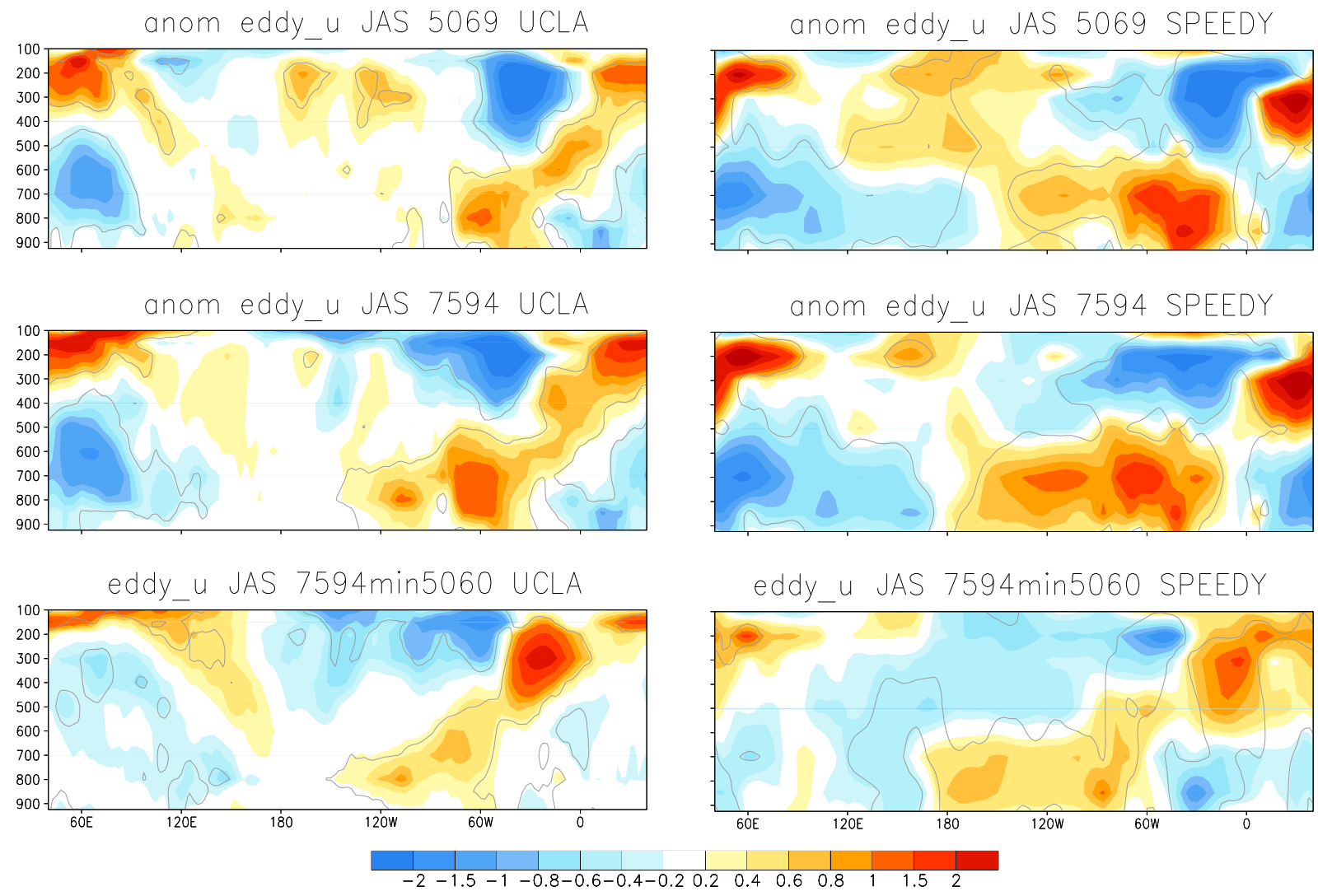

Figure 10: Longitude by height section of anomalous JAS zonal wind $(\mathrm{m} / \mathrm{s})$ averaged between 4S-4N for ATL_pre70 (first row) and ATL_post70 (second row) simulations and the difference between them (third row) for UCLA (left) and ICTP (right) models. Gray lines denote those regions where the anomalies are significant at a 95\% confidence level. 
anom eddy_u925 JAS 5069 UCLA

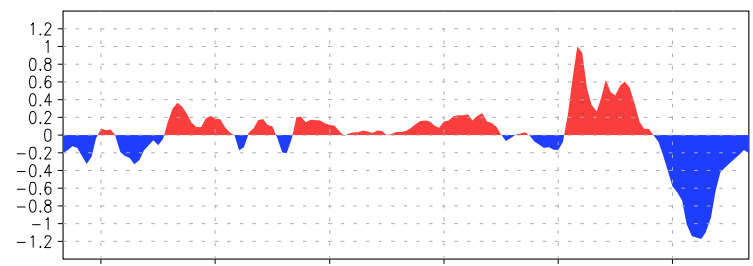

anom eddy_u925 JAS 7594 UCLA

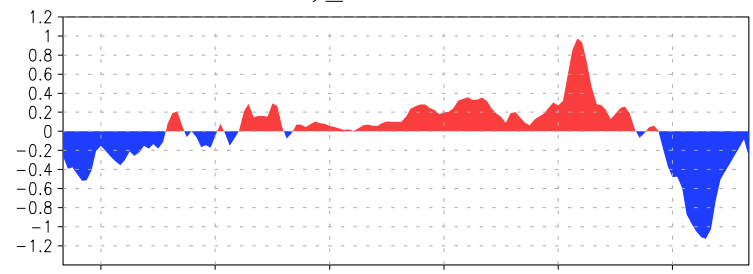

anom eddy_u925 JAS 7594 min5060 UCLA

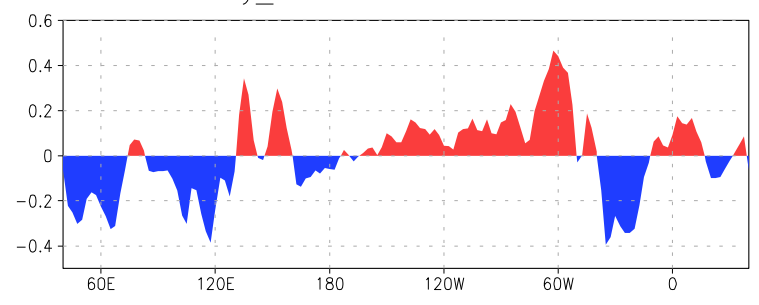

anom eddy_u925 JAS 5069 SPEEDY

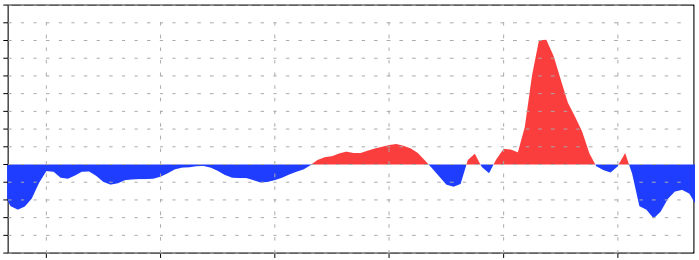

anom eddy_u925 JAS 7594 SPEEDY

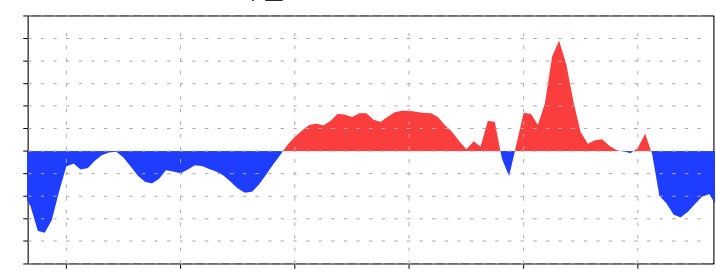

anom eddy_u925 JAS 7594 min5060 SPEEDY

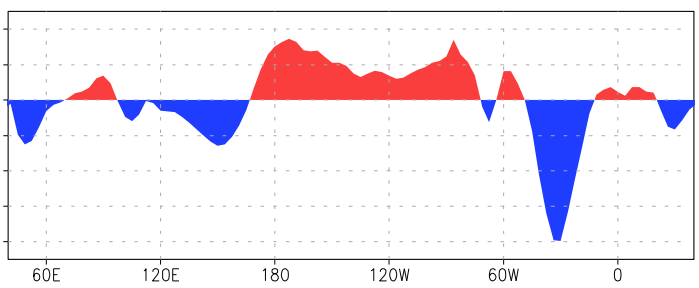

Figure 11: Longitude section of anomalous JAS zonal-averaged zonal wind $(\mathrm{m} / \mathrm{s})$ at the equator for ATL_pre70 (first row) and ATL_post70 (second row) simulations and the difference between them (third row) for UCLA (left) and ICTP (right) models. 